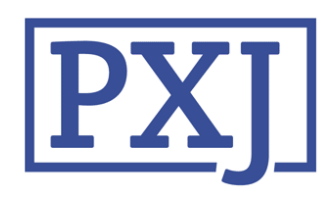

Patient Experience Journal

Volume 8

Issue 2 The Impact of Inequity \& Health

Disparities on the Human Experience

Article 11

2021

\title{
The experience, satisfaction, and Emergency Department utilization of pediatric patients with sickle cell disease during the Covid-19 pandemic
}

Alexandra E. Kirsch

St. Christopher's Hospital for Children

Nataly Apollonsky

St. Christopher's Hospital for Children

Follow this and additional works at: https://pxjournal.org/journal

Part of the Pediatrics Commons

\section{Recommended Citation}

Kirsch AE, Apollonsky N. The experience, satisfaction, and Emergency Department utilization of pediatric patients with sickle cell disease during the Covid-19 pandemic. Patient Experience Journal. 2021;

8(2):78-83. doi: 10.35680/2372-0247.1608.

This Research is brought to you for free and open access by Patient Experience Journal. It has been accepted for inclusion in Patient Experience Journal by an authorized editor of Patient Experience Journal. 
The experience, satisfaction, and Emergency Department utilization of pediatric patients with sickle cell disease during the Covid-19 pandemic

\section{Cover Page Footnote}

This article is associated with the Quality \& Clinical Excellence lens of The Beryl Institute Experience Framework (https://www.theberylinstitute.org/ExperienceFramework). You can access other resources related to this lens including additional PXJ articles here: http://bit.ly/PX_QualityClinExc 


\title{
The experience, satisfaction, and Emergency Department utilization of pediatric patients with sickle cell disease during the Covid-19 pandemic Alexandra E. Kirsch, St. Christopher's Hospital for Children, alexandra.kirsch@towerhealth.org Nataly Apollonsky, St.Christopher's Hospital for Children,nataly.apollonsky@towerhealth.org
}

\begin{abstract}
The COVID-19 pandemic has influenced how patients utilize healthcare. This study examines the utilization, experience, and satisfaction of patients with Sickle Cell Disease (SCD) in the pediatric Emergency Department (ED) during the COVID-19 pandemic compared to the care they had received before the pandemic. The authors surveyed fifty-eight participants ages 14 months to 20 years who presented to the ED for a complaint related to their SCD during the COVID-19 pandemic. The study analyzed five variables: race, SCD severity, hemoglobin (Hgb) genotype, who completed the questionnaire (patient versus parent/guardian), and whether the ED visit resulted in an admission to the hospital. Our results suggest that the COVID-19 pandemic significantly affected the decision of some patients as to whether and when to go to the ED. African Americans and those with severe disease did not wait longer than usual to go to the ED, possibly because these groups are more likely to have more serious and more frequent pain crises. Thus, their decision to present to the ED was driven more by their relatively worse symptoms, rather than such external factors as the pandemic. However, the pandemic did not significantly affect patients' satisfaction with their ED visit or their baseline SCD symptoms. To our knowledge, this is the first study of how the COVID-19 pandemic has affected patients' utilization of, experience in, and satisfaction with a pediatric hospital ED.
\end{abstract}

\section{Keywords}

Patient experience, patient satisfaction, patient utilization, COVID-19, pediatric, emergency department, sickle cell disease

\section{Introduction}

There are approximately 100,000 people in the United States afflicted with the group of inherited hemoglobinopathies known collectively as sickle cell disease (SCD). ${ }^{1}$ The vast majority of patients with SCD are of African or Hispanic descent. Nationally, patients with SCD account for approximately 200,000 Emergency Department (ED) visits annually. ${ }^{2}$ Patients with SCD may suffer from numerous complications including chronic pain, progressive multi-system organ damage, retinopathy, embolism and stroke, acute chest syndrome, and increased susceptibility to life-threatening infections, especially in the pediatric population. ${ }^{2-3}$ Acute pain exacerbation due to a vaso-occlusive crisis is the most common reason for patients with SCD to visit the ED and often requires treatment with parenteral opioid medication. ${ }^{2-4}$

Patients with SCD who contract SARS-CoV-2 have a higher risk of complications, severe disease course, and death compared to the general population. ${ }^{5}$ In a study of 178 patients with SCD and COVD-19 infection reported to the SECURE-SCD registry between March and May 2020, Panepinto and colleagues found that $90 \%$ of patients accessed care through an ED, 69\% required hospitalization, $11 \%$ were admitted to an intensive care unit, and 7\% died. ${ }^{5}$ Thus, patients with SCD who delay or avoid seeking emergency medical care due to the COVID19 pandemic may be at an increased risk of adverse outcomes.

The National Syndromic Surveillance Program found that ED visits decreased $42 \%$ overall during the early stages of the COVID-19 pandemic. ${ }^{6}$ Patients with SCD have consistently expressed a significant level of dissatisfaction regarding the ED care they have received, especially when compared to the care that these patients have received from their usual physician. ${ }^{7-8}$ The multifactorial reasons that patients with SCD are dissatisfied with ED care include, but are not limited to, long wait times that may result in treatment delays, lack of communication and comanagement between the ED and patients' primary medical provider, perceived lack of empathy, absence of standardized treatment protocols, ED provider attitudes and discomfort with acute pain management in this patient population, and inadequate analgesic dosing. ${ }^{7-8}$ The wellestablished negative perception of ED care raised the question of the COVID-19 pandemic's impact on the decision-making process of patients with SCD. This study examines whether and when patients with SCD sought ED care and their satisfaction with and experience in the

Patient Experience Journal, Volume 8, Issue 2 - Special Issue: The Impact of Inequity \& Health Disparities on the Human Experience (C) The Author(s), 2021. Published in association with The Beryl Institute.

Downloaded from www.pxjournal.org 
ED during the COVID-19 pandemic compared to the ED care that they received before the pandemic.

Very few studies have focused on pediatric patients with sickle cell disease and healthcare utilization during the COVID-19 pandemic. Tsitsikas and colleagues evaluated the strategy of preventing hospitalizations and extended hospitalizations in the United Kingdom. ${ }^{9}$ One study surveyed providers at 28 practices to determine how the COVID-19 pandemic affected outpatient care of patients with SCD.${ }^{10}$ Another study assessed the level of anxiety of adolescents and young adults with SCD to evaluate the correlation between COVID-19 experiences, anxiety levels, and painful episodes. ${ }^{11}$ Finally, one study evaluated how the pandemic and stay-at-home orders affected ED visits to a tertiary care hospital; although this study reviewed all patients presenting to the $\mathrm{ED}$, there was a small subset who had sickle cell disease. ${ }^{12}$ To our knowledge, this is the first study to investigate the effect of the COVID-19 pandemic on the utilization of, experience in, and satisfaction with Emergency Department services by pediatric patients with sickle cell disease.

\section{Materials and Methods}

\section{Participants}

Potential study participants were identified from patients with a diagnosis of SCD who were followed long-term at the Marian Anderson Sickle Cell Center at St. Christopher's Hospital for Children. The center maintains a database of its patients; the authors mined the database to identify patients with SCD who visited the ED for a complaint related to their SCD during the COVID-19 pandemic (February 2020 - March 2021). Potential participants were contacted to verify the information, ensure that they met the inclusion criteria, and were willing to participate in the study.

A total of 58 participants were included in the study. Of these, $23(40 \%)$ were female and $35(60 \%)$ were male. The ages ranged from 14 months to 20 years $(\mathrm{m}=13.8$ years, $\mathrm{SD}=5.98$ years)

Most of the patients had sickle cell SS ( $\mathrm{n}=27 ; 47 \%$ ), followed by SC ( $\mathrm{n}=20 ; 35 \%), \mathrm{S} \beta^{+}$thalassemia, $(\mathrm{n}=7$, $12 \%), \mathrm{S} \beta^{0}$ thalassemia $(\mathrm{n}=2 ; 3 \%)$ and $\mathrm{S} / \mathrm{HPFH}(\mathrm{n}=2$; $3 \%$ ). The disease was classified as severe if patients had more than three hospital admissions in a year, cerebral vasculopathy, chronic packed red blood cell transfusions, or a history of acute chest syndrome in the last three years. Most patients were classified as not severe $(n=40 ; 69 \%)$ rather than severe $(n=18 ; 31 \%)$. Most of the participants were African American ( $\mathrm{n}=48 ; 83 \%$ ) followed by Hispanic ( $\mathrm{n}=6 ; 10 \%)$ and those who self-identified as "other" ( $n=4 ; 7 \%)$. Table 1 summarizes the demographics of the participants.

\section{Table 1. Patient Demographics}

\begin{tabular}{|c|c|c|}
\hline $\begin{array}{l}\text { Gender }^{\mathrm{a}} \\
\text { Age in years }\end{array}$ & $\begin{array}{l}\text { Variable } \\
\text { Female } \\
\text { Male }\end{array}$ & $\begin{array}{l}\mathrm{n}(\%) \text { or mean }(\mathrm{SD}) \\
23(40 \%) \\
35(60 \%) \\
13.8(5.98)\end{array}$ \\
\hline Hgb Genotype & $\begin{array}{l}\mathrm{SS} \\
\mathrm{SC} \\
\mathrm{S} \beta^{+} \text {thalassemia } \\
\mathrm{S} \beta^{0} \text { thalassemia } \\
\mathrm{S} / \mathrm{HPFH}\end{array}$ & $\begin{array}{l}27(47 \%) \\
20(35 \%) \\
7(12 \%) \\
2(3 \%) \\
2(3 \%)\end{array}$ \\
\hline Disease Severity & $\begin{array}{l}\text { Severe } \\
\text { Not Severe }\end{array}$ & $\begin{array}{l}18(31 \%) \\
40(69 \%)\end{array}$ \\
\hline Race $^{\mathrm{b}}$ & $\begin{array}{l}\text { African American } \\
\text { Hispanic } \\
\text { Other }\end{array}$ & $\begin{array}{l}48(83 \%) \\
6(10 \%) \\
4(7 \%)\end{array}$ \\
\hline
\end{tabular}


Table 2. Likert Questionnaire Responses Scored from Strongly Disagree (1) to Strongly Agree (5)

\begin{tabular}{|c|}
\hline $\begin{array}{l}\text { 1) My decision to go to the Emergency Room was } \\
\text { affected by the COVID pandemic. }\end{array}$ \\
\hline $\begin{array}{l}\text { 2) I waited longer before going to the Emergency } \\
\text { Room (vs. before the pandemic). }\end{array}$ \\
\hline $\begin{array}{l}\text { 3) I tried more medications at home for fever and/or } \\
\text { pain (vs. before the pandemic). }\end{array}$ \\
\hline $\begin{array}{l}\text { 4) My experience in the Emergency Room was better } \\
\text { during the pandemic (vs. before the pandemic). }\end{array}$ \\
\hline $\begin{array}{l}\text { 5) I got to a room and/or got care faster during the } \\
\text { pandemic (vs. before the pandemic). }\end{array}$ \\
\hline $\begin{array}{l}\text { 6) I felt the hospital took the proper COVID-related } \\
\text { precautions (e.g., staff wore masks, ER was cleaned } \\
\text { regularly, etc.). }\end{array}$ \\
\hline $\begin{array}{l}\text { 7) I feel like my Sickle Cell Disease symptoms (pain, } \\
\text { fever, etc.) are milder now (vs. before the pandemic). }\end{array}$ \\
\hline
\end{tabular}

\section{Intervention}

Patient responses to their experience in and satisfaction with a recent Emergency Department visit were recorded using a specifically-designed Likert questionnaire (Table 2). Telephone interviews were conducted in lieu of in-person interviews due to social distancing and safety measures implemented during the COVID-19 pandemic. The responses to these seven questions were graded on a 1 to 5 Likert scale, with 1 signifying strong disagreement and 5 signifying strong agreement (Table 2). Analysis of covariance was performed to compare means. The remaining four questions, numbered 8 through 12, were open-ended or yes/no questions (Table 3). For these purposes, patient experience is defined as something that happened to a patient, or how something happened while patient satisfaction refers to patients' expectations and whether they were met. As depicted in Table 2, questions 4 and 5 relate to patient experience, while the other questions relate to patient satisfaction. The data were analyzed as a whole and also grouped by five variables: race, SCD severity, Hgb genotype, who completed the questionnaire (parent/guardian versus patient), and whether the ED visit resulted in hospital admission. An ED visit that resulted in hospital admission was thought to be severe enough to require inpatient management and thus was used as a surrogate for the severity of an episode. Two-tailed $\mathrm{p}$-values less than 0.05 were considered statistically significant.

To provide the context of the patient experience relevant to this study, patients with SCD who present to the St.
Table 3. Open-Ended and Yes/No Questions

8) My answers to one (or more) of the choices above are different now than it would have been at the beginning of the COVID-19 pandemic.

If Yes, Question number:

My score would have been:

9) My biggest concern about going to the Emergency Room was (circle all that apply):

(a) waiting area (b) registration

(c) other patients (d) providers (e) admissions

10) I was screened for COVID symptoms when I arrived at the Emergency Room: Y / N

11) I used telemedicine (video or telephone appointment) during the pandemic: $\mathrm{Y} / \mathrm{N}$ If Yes, how was the experience?

Christopher's Hospital for Children ED are evaluated and treated according to a standardized algorithm. For patients with SCD and a fever greater than or equal to 38.5 degrees Celsius, intravenous access is obtained, an appropriate workup is initiated, and broad-spectrum intravenous antibiotics are begun within one hour of arrival. For patients with SCD and pain, patients are given intravenous analgesics within 20 to 30 minutes of registration. The treatment algorithms were not changed during the COVID pandemic. However, new patient social distancing and COVID-related safety measures were implemented beginning in April 2020 and remain in place. All patients and guardians are briefly interviewed upon arrival to the ED to assess COVID-19 risk factors including pertinent symptoms, recent travel, exposure to a suspected or confirmed COVID-positive patient, and whether there is a pending COVID-19 test. All patients and visitors to the ED are screened for body temperature. All patients with SCD who admitted from the ED to an inpatient bed undergo a COVID-19 polymerase chain reaction (PCR) test.

\section{Results}

Fifty-eight patients participated in the study. The overall results for the first seven Likert-scale questions are depicted in Table 4. Most patients reported that their decision to go to the Emergency Room was affected by the COVID-19 pandemic $(n=38 ; 62 \%)$. The responses to question 1 were statistically significant across all groups except for race. There were significant differences when 
patient responses were analyzed by hemoglobin genotype (mean $=3.04$ for Hgb SS versus a mean $=3.77$ for other genotypes, $\mathrm{p}=0.047$ ), whether the parent/guardian or patient completed the questionnaire (mean $=2.72$ for parents /guardians, mean $=3.75$ for patients, $\mathrm{p}=0.01$ ), whether a patient was admitted (mean $=3.11$ for admitted patients versus a mean $=3.91$ for those patients discharged from the ED, $\mathrm{p}=0.034$ ), as well as disease severity (mean $=2.83$ for severe disease versus mean $=$ 3.70 for disease considered as not severe, $\mathrm{p}=0.03$ ). These results are illustrated in Figure 1.

Most participants responded that their experience in the ED was the same during the pandemic as it was before the pandemic ( $\mathrm{n}=45,78 \%$ ) (Table 4$)$. The results were statistically significant when analyzed by Hgb genotype (mean $=3.37$ for Hgb SS versus a mean $=3.06$ for other genotypes, $\mathrm{p}=0.046$ ) (Figure 1). Most participants stated that there was no change in the time it took to get an ED bed or to receive medical care $(n=35 ; 60 \%)$ (Table 4). All patients reported that they felt the ED personnel took proper infectious precautions $(n=58 ; 100 \%)$ (Table 4). Overall, most participants felt their baseline sickle cell disease symptoms were unchanged compared to before the pandemic $(n=41 ; 70 \%)$ (Table 4$)$.

All participants were asked if they would answer the survey differently at the time that it was administered compared to at the beginning of the pandemic (Table 3). Five participants responded, and all felt differently about their decision to go to the ED. Two participants were more worried about returning to ED during the pandemic, and three participants were more comfortable going to the ED. Twenty-four participants responded to question 9 about their biggest concern for their ED visit. Most were worried about other patients $(n=18)$, followed by the waiting area $(n=13)$, then ED providers $(n=2)$. All but 2 of the participants remembered being screened for COVID-19 exposure and symptoms $(n=56$; 97\%). Most participants did not choose to utilize telemedicine during the pandemic $(n=39 ; 67 \%)$. Many participants

commented that the wait to see a provider in the ED was not longer than usual, but the wait to get a hospital room after admission was longer than usual, most likely due to the time it took to obtain the results of COVID-19 PCR testing.

Figure 1. Responses to Likert Questions 1 through 5, Analyzed by Subgroups

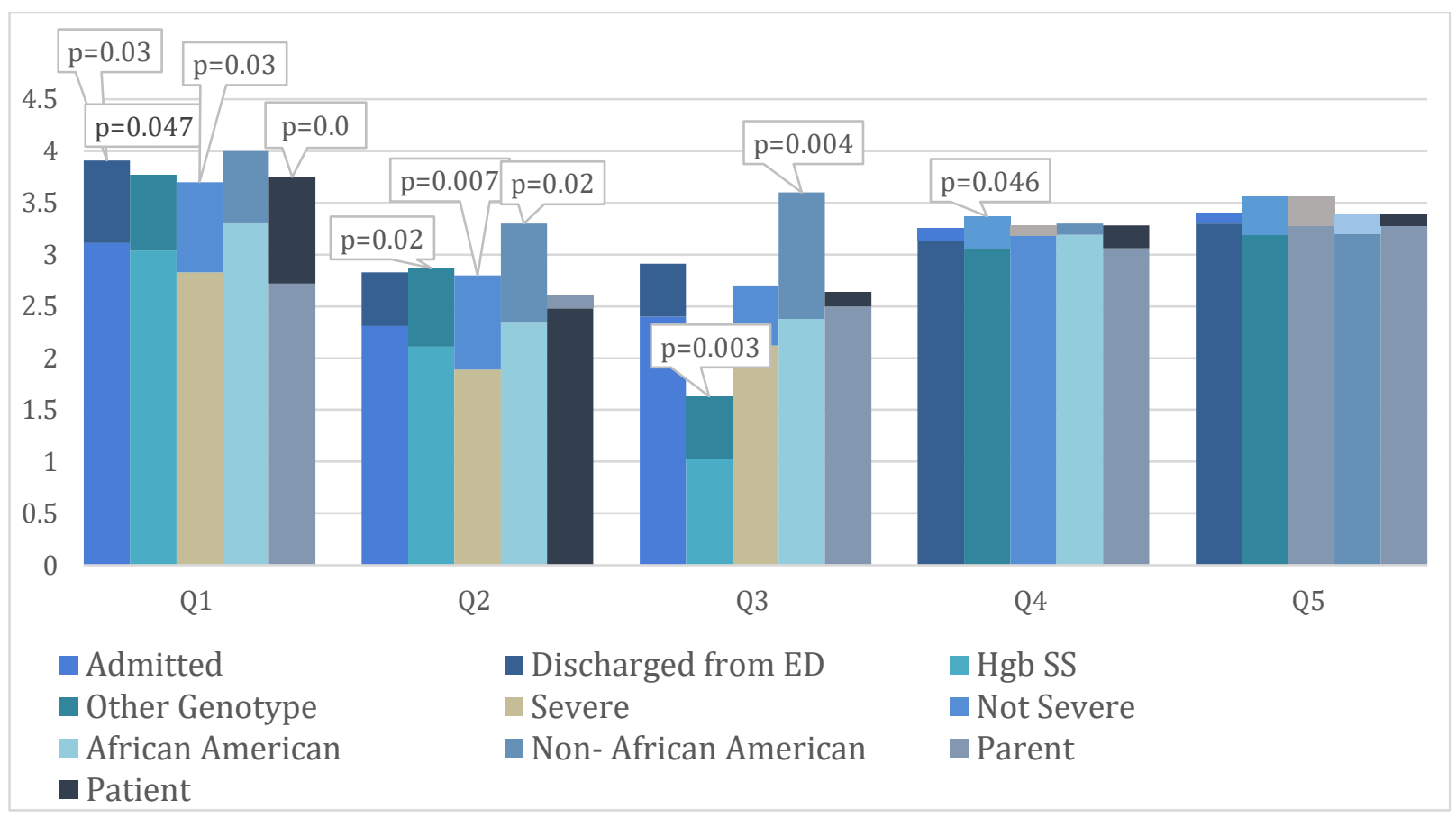

Subgroup analysis of response organized by question. 1) My decision to go to the Emergency Room was affected by the COVID-19 pandemic. 2) I waited longer before going to the Emergency Room (vs. before pandemic). 3) I tried more medications at home for fever and/or pain (vs. before the pandemic). 4) My experience in the Emergency Room was better during the pandemic (vs. before the pandemic). 5) I got to a room in the ED and/or got care faster during the pandemic (vs. before the pandemic). 


\section{Table 4. Responses to Likert Questions}

\begin{tabular}{|c|c|c|c|c|c|c|}
\hline \multirow[b]{2}{*}{ Question } & \multirow[b]{2}{*}{ Mean (SD) } & \multicolumn{5}{|c|}{$\mathrm{n}(\%)$} \\
\hline & & Strongly Disagree & Disagree & Neutral & Agree & Strongly Agree \\
\hline 1 & $3.43(1.41)$ & $11(19 \%)$ & $3(5 \%)$ & $8(14 \%)$ & $22(38 \%)$ & $14(24 \%)$ \\
\hline 2 & $2.52(1.22)$ & $18(31 \%)$ & $8(14 \%)$ & $17(29 \%)$ & $14(24 \%)$ & $1(2 \%)$ \\
\hline 3 & $2.60(1.25)$ & $16(28 \%)$ & $9(16 \%)$ & $17(30 \%)$ & $12(21 \%)$ & $3(5 \%)$ \\
\hline 4 & $3.21(0.59)$ & $0(0 \%)$ & $2(3 \%)$ & $45(78 \%)$ & $8(14 \%)$ & $3(5 \%)$ \\
\hline 5 & $3.36(0.77)$ & $0(0 \%)$ & $4(7 \%)$ & $35(60 \%)$ & $13(23 \%)$ & $6(10 \%)$ \\
\hline 6 & $5.00(0)$ & $0(0 \%)$ & $0(0 \%)$ & $0(0 \%)$ & $0(0 \%)$ & $58(100 \%)$ \\
\hline 7 & $3.03(0.59)$ & $0(0 \%)$ & $8(14 \%)$ & $41(70 \%)$ & $8(14 \%)$ & $1(2 \%)$ \\
\hline $\begin{array}{l}\text { 1) My deci } \\
\text { 2) I waited } \\
\text { 3) I tried } n \\
\text { 4) My exp } \\
\text { 5) I got to } \\
\text { 6) I felt th } \\
\text { 7) I feel lik }\end{array}$ & $\begin{array}{l}\text { to go to th } \\
\text { ger before } \\
\text { medication } \\
\text { tce in the E } \\
\text { om in the } \\
\text { spital took } \\
y \text { sickle cell }\end{array}$ & $\begin{array}{l}\text { ergency Room was } \\
\text { to the Emergency } \\
\text { ome for fever and } \\
\text { ency Room was bet } \\
\text { d/or got care faste } \\
\text { oper infectious pre } \\
\text { se symptoms (pain }\end{array}$ & $\begin{array}{l}\text { ected by } \\
\text { m (vs. b } \\
\text { pain (vs. } \\
\text { during th } \\
\text { rring the } \\
\text { tions (sta } \\
\text { er, etc.) }\end{array}$ & $\begin{array}{l}\text { OVID-19 } \\
\text { pandemic) } \\
\text { ee the pand } \\
\text { idemic (vs. } \\
\text { emic (vs. b } \\
\text { re masks, I } \\
\text { ilder now }\end{array}$ & $\begin{array}{l}\text { mic. } \\
\text { e the pande } \\
\text { the pandem } \\
\text { s cleaned } r \\
\text { fore the par }\end{array}$ & $\begin{array}{l}\text { trly, etc.). } \\
\text { aic). }\end{array}$ \\
\hline
\end{tabular}

\section{Discussion}

Our results suggest that the COVID-19 pandemic has not significantly affected patients' experience in and satisfaction with ED visits or their baseline SCD symptoms. Overall, most people felt that the COVID-19 pandemic affected their decision to go to the Emergency Room, which was also notable when analyzed by subgroup. Patients with Hgb SS genotype, severe disease, patients who were subsequently admitted to the hospital, and parents responding to the survey were less affected by the pandemic in their decision-making process. One possible explanation is that patients who have the Hgb SS genotype and severe disease are more likely to have more serious and more frequent pain crises. Thus, their decision to present to the ED was driven more by their relatively worse symptoms, rather than such external factors as the pandemic, compared to participants with other genotypes and less severe disease. Using admission to the hospital as a surrogate for episode severity, it can be argued that patients who were having more severe episodes or crises were less hesitant to go to the ED. Finally, when considering who responded to the survey, recall bias and parental concern may account for parents wishing to take their children to the Emergency Room regardless of the additional risks posed by the COVID-19 pandemic.

Interestingly, most participants did not wait longer than usual before going to the ED and took the same amount of medication for pain or fever as they usually did during the pandemic. Those patients with Hgb SS, severe disease, and who self-identified as African American were less likely to have waited before going to the ED. In addition, those patients with Hgb SS and who self-identified as African American were less likely to have taken more medication before going to the ED as compared to before the pandemic. These subgroups are more likely to have more serious and frequent pain crises, which may account for the observation that they did not delay in seeking medical care. Given the evidence that patients with SCD have a much higher risk of significant morbidity and mortality if they were to contract SARS-CoV-2 than patients without $S C D$, it is imperative that patients with SCD do not defer seeking appropriate, emergent medical attention. ${ }^{5}$

Although there is a substantial level of dissatisfaction with ED care that has been well documented among the population of patients with $\mathrm{SCD}$, our results indicate that the COVID-19 pandemic did not worsen patients' experience or satisfaction with their care. ${ }^{7-8}$ Most of the participants in this study reported that their experience in the ED was similar to their ED experiences before the pandemic, especially for those with the Hgb SS genotype. All respondents reported that the hospital took appropriate sanitary and social distancing precautions implemented during the pandemic. This result is further supported by most respondents not being concerned about staying in the waiting room or by the ED providers, but expressing concern about the potential risk posed by 
other patients. Our results infer that, as most patients did not have a more negative experience in the ED during the pandemic, they would not be opposed to returning to the ED if necessary.

Overall, most participants felt their baseline sickle cell disease symptoms were unchanged compared to before the pandemic. One theory for the decrease in ED visits by patients with SCD during the pandemic is that such protective measures such as mask-wearing and social distancing result in less spread of viral respiratory illnesses in general, thereby leading to fewer SCD exacerbations. Our data do not support this theory. Most participants stated that there was no change in the time it took to get an ED bed or to get medical care. Interestingly, most participants did comment on the long wait time to get an inpatient bed assigned, most likely due to the time it took to run a COVID-19 PCR test per hospital protocol.

There are limitations to the study. The survey was conducted with a relatively small sample size of patients with SCD who were seen at a single pediatric ED. Therefore, care should be taken when generalizing our results. There is a risk of recall bias as the survey questioned participants about a past ED visit. The study was retrospective, as are most survey studies.

Despite the above limitations, this study is meaningful given the consistently negative ED encounters historically reported by patients with SCD. The results imply that the COVID-19 pandemic did not deter those pediatric patients with SCD who needed emergency care from seeking it, and that their experience and satisfaction with the ED was not substantially impacted by the additional screening and safety protocols implemented during the pandemic. To our knowledge, this is the first study of how the COVID-19 pandemic has affected patients' utilization of, experience in, and satisfaction with a pediatric hospital ED.

\section{References}

1. Centers for Disease Control and Prevention. 2021. Sickle Cell Data Collection (SCDC) Program | CDC. [online] Available at:

<https://www.cdc.gov/ncbddd/hemoglobinopathies /scdc.html> [Accessed 12 July 2021].

2. Crego N, Masese R, Bonnabeau E, et al. "Patient perspectives of sickle cell management in the emergency department." Crit Care Nurs Q. 2021; 44(2): 160-174. doi:10.1097/CNQ.0000000 000000350

3. Lovett PB, Sule HP, Lopez BL. "Sickle cell disease in the emergency department." Hematol Oncol Clin North Am. 2017; 31(6): 1061-1079. doi: 10.1016/j.emc.2014.04.011

4. Shah N, Bhor M, Xie L, Paulose J, Yuce H. "Sickle cell disease complications: Prevalence and resource utilization.” PloS One. 2019; 14 (7) e0214355. doi:10.1371/journal.pone.0214355

5. Panepinto JA, Brandow A, Mucalo L, et al. "Coronavirus disease among persons with sickle cell disease, United States, March 20-May 21, 2020.” Emerg Infect Dis. 2020;26(10): 2473-2476. doi: 10.3201 / eid 2610.202792.

6. Centers for Disease Control and Prevention. 2021. Emergency Department Visits Percentage of Visits for COVID-19-Like Illness (CLI) or Influenza-like Illness (ILI). [online] Available at: <https://www.cdc.gov/coronavirus/2019ncov/covid-data/covidview/10022020/covid-likeillness.html> [Accessed 5 April July 2021].

7. Kanter J, Gibson R, Lawrence RH, et al. "Perceptions of US adolescents and adults with sickle cell disease on their quality of care." JAMA Netw Open. 2020;3(5): e206016, doi:10.1001/jama networkopen.2020.6016

8. Cacciotti C, Vaiselbuh S, Romanos-Sirakis E. Pain management for sickle cell disease in the pediatric emergency department: medications and hospitalization trends. Clin Pediatr. 2016;56 (12):1109_ 1114. doi: 10.1177/0009922816674521.

9. Tsitsikas DA, Lewis N, McCloskey K, et al. Remodeling of specialist services enables safe reduction in hospital admissions of patients with sickle cell disease: Lessons from the COVID-19 pandemic. Clin Med (Lond). 2020;20(6):e241-e243. doi: 10.7861/clinmed.2020-0474.

10. Noisette ML, Phillips S, Schlenz AM, Mueller M, Kanter J. Changes in care delivery for children with sickle cell anemia during the COVID-19 pandemic. [Published online ahead of print November 23 2020]. J Pediatr Hematol Oncol. 2020. doi: 10.1097/MPH.0000000000002008

11. Tezol O, Unal S. Anxiety level and clinical course of patients with sickle cell disease during the COVID-19 outbreak. Arch Pediatr. 2021; 28(2): 136-140. doi: 10.1016/j.arcped.2020.12.004.

12. Chaiyachati BH, Agawu A, Zorc JJ, Balamuth F. Trends in pediatric emergency department utilization after institution of coronavirus disease-19 mandatory social distancing. J Pediatr. 2020; 226: 274-277. doi: 10.1016/j.jpeds.2020.07.048 